Revista de Economia Política, vol. 36, nº 1 (142), pp. 70-90, janeiro-março/2016

\title{
Reflexões sobre o método em Keynes
}

\author{
Reflections on the method of Keynes
}

\author{
FERNANDO FERRARI FILHO \\ FÁBIO HENRIQUE BITTES TERRA*
}

RESUMO: Provavelmente, a questão do método seja uma das mais controvertidas discussões relacionadas à obra de Keynes. As controvérsias podem ser resumidas em três principais linhas: (i) o atomismo ou o organicismo como unidade de análise econômica de Keynes; (ii) a continuidade ou a descontinuidade das bases filosóficas, em termos epistemológicos e metodológicos, do pensamento de Keynes; e (iii) a especulação acerca do método científico utilizado por Keynes. O objetivo do artigo centra-se na última das linhas da controvérsia, qual seja, discutir o método científico na obra de Keynes. Subjacente a tal objetivo, apesar dos indícios de que o método do autor está relacionado tanto ao indutivo quanto ao histórico-indutivo, explorar-se-á o primeiro método, uma vez que, por um lado, ele diz respeito à teoria do conhecimento (epistemologia) desenvolvida por Keynes em seu Treatise on Probability e, por outro lado, ele está presente em algumas de suas importantes obras econômicas.

PALAVRAS-CHAVE: Keynes; Teoria Keynesiana; Metodologia Científica.

ABASTRACT: The question of method raises probably some of the most controversial discussions of the work of John Maynard Keynes. Briefly, the controversies fall into three main areas: (i) the unit of analysis, i.e., whether Keynes' economic theory is atomistic or organic; (ii) whether or not there is continuity in Keynes' philosophical foundations throughout his work; and (iii) speculation about the scientific method Keynes used. In that context, this paper aims to explore the latter of these lines of controversy. The idea is to show that, considering his insights related to the inductivism, mainly in the Treatise on Probability, there are evidences that Keynes' method was historical and inductive.

KEYWORDS: Keynes; Keynesian Theory; Scientific Methodology.

JEL Classification: B2; B4; E 12.

\footnotetext{
* Respectivamente, Professor titular da Universidade Federal do Rio Grande do Sul (UFRGS), Porto Alegre, RS - Brasil e pesquisador do CNPq. E-mail: Ferrari@ufrgs.br; Professor adjunto da Universidade Federal de Uberlândia, Uberlândia, MG - Brasil. E-mail:fhbterra@gmail.com. Submetido: 7/Março/2014; Aprovado: 17/Outubro/2014
} 
I have derived valuable assistance from unpublished writings of G. E. Moore and J. M. Keynes: from the former as regards the relations of sense-data to physical objects, and from the latter as regards probability and induction.

(Bertrand Russell, prefácio do The Problems of Philosophy, 1912)

\section{INTRODUÇÃO ${ }^{1}$}

$\mathrm{Na}$ busca pelo conhecimento, o método científico cumpre papel fundamental, pois é o meio regrado e ordenado pelo qual o sujeito aborda um objeto desconhecido - o fenômeno - ansiando circunscrevê-lo a ponto de compreendê-lo e com ele estabelecer uma relação de conhecimento. As técnicas e normas que o método envolve devem ser aceitas pela comunidade científica e funcionam como alicerces para que o conhecimento obtido seja válido. Assim sendo, o método define os procedimentos que permitem compreender as características de um fenômeno, tanto para apreendê-lo em si quanto para entender suas relações de semelhança, dessemelhança, causas e efeitos uni ou multideterminados, com outros objetos.

O debate sobre o método em John Maynard Keynes tomou corpo nos anos 1980 como resultado do resgate teórico dos escritos originais do autor, reunidos e publicados nos Collected Writings of John Maynard Keynes (CWJMK), por parte da teoria pós-keynesiana. Não obstante, talvez seja a referida questão uma das mais controversas nas várias interpretações sobre as ideias e concepções teóricas de Keynes, haja vista a diversidade de posições sobre qual seria o seu método. Sem a pretensão de simplificar o debate, é possível resumi-lo em três principais linhas, quais sejam: (i) o atomismo ou o organicismo como unidade de análise da teoria econômica de Keynes; (ii) a continuidade ou a descontinuidade das bases filosóficas, em termos epistemológicos e metodológicos, do pensamento de Keynes ao longo de sua obra; e (iii) a especulação acerca do método científico utilizado por Keynes.

Cada uma destas linhas tornou-se uma agenda de pesquisa que, embora com inerente interface, possui desenvolvimentos próprios e circunscritos aos objetos em debate. Citem-se, por exemplo, nas discussões sobre o atomismo ou organicismo, as controvérsias entre Bateman (1989) e Davis (1989-1990), favoráveis ao atomismo, e Carabelli (1985) e Winslow (1986, 1989a, 1989b) e Rotheim (1989-1990), em acordo com o organicismo. Por sua vez, os trabalhos de O'Donnell $(1989,2002)$ se destacam no que se refere à continuidade nos princípios filosóficos que fundamentam uma determinada visão de mundo de Keynes, enquanto que Bateman $(1989,1991)$ propõe a ruptura e Gerrard (1992) e Carvalho (1992) denotam tanto rupturas quanto continuidades.

\footnotetext{
${ }^{1}$ Os autores gostariam de agradecer a dois pareceristas anônimos pelas críticas e sugestões. Naturalmente, os erros remanescentes são de responsabilidade única dos autores.
} 
O objetivo do artigo centra-se na última das linhas de controvérsia, isto é, discutir o método científico utilizado por Keynes. Como traço distintivo e ao mesmo tempo contributivo à literatura pertinente, o artigo se restringe a explorar o princípio da indução e, por conseguinte, o método indutivo na obra de Keynes, sob o argumento de que os referidos princípio e método, por um lado, foram desenvolvidos por ele na teoria do conhecimento (epistemologia) apresentada em seu Treatise on Probability (TP) e, por outro lado, estão presentes em suas obras econômicas. Em especial, o artigo mostra que, para Keynes, o princípio da indução era composto pelas analogia e indução pura, sendo que esta última está relacionada ao método histórico-indutivo, destacado pela teoria pós-keynesiana como o método comumente utilizado por Keynes em sua obra. ${ }^{2}$

No entanto, parte-se do pressuposto de que, em virtude de sua vasta e eclética produção, seria difícil o método histórico-indutivo ter sido o único utilizado por Keynes, muito embora seja tal método bastante pertinente ao característico pragmatismo do autor. Não é por menos que a teoria pós-keynesiana não trata a indução per si como o método de Keynes, mas destaca que o autor se debruçou sobre o fenômeno econômico a partir da observação do tempo histórico do real world, conforme o método histórico-indutivo, a que, por sua vez, Bresser-Pereira $(2012)^{3}$ chamou de método histórico-dedutivo, ao argumentar que a ciência econômica tem que ser modesta, racional e pragmática, para que sirva como instrumento compreensível de intervenção política sobre a realidade.

A despeito da diferença dos autores acima mencionados, este artigo utilizará o termo indução como insight/referência para especular-se sobre o método indutivo (ou histórico-indutivo) em Keynes, ${ }^{4}$ pois, assim, o autor o faz na TP, ao defender e mostrar as condições de validade deste método, esforço este que alcançou a ressonância ilustrada pela epígrafe deste artigo. Como se buscará mostrar, a indução foi defendida e utilizada por Keynes, em âmbito individual, como um importante meio de se investigar a racionalidade e o comportamento epistemológico humano, tanto quanto, em nível macroeconômico, para entender o funcionamento do sistema econômico.

\footnotetext{
2 Para maiores detalhes, veja Davidson (1972), Eichner (1984), Robison (1984), Chick (1998), Dow (2001) e Chick e Dow (2001).

${ }^{3}$ Conforme Bresser-Pereira (2012, p. 299), “economia deve ser uma ciência modesta, uma ciência racional e uma ciência pragmática. Uma ciência modesta porque [...] relações [são] [...] confrontadas com a realidade [...] [porque] estrutura e instituições estão em permanentes mudanças [...] [e] incerteza [...] [faz parte] do comportamento econômico. Uma ciência razoável porque homens e mulheres são seres racionais [...] E uma ciência pragmática porque crescimento e estabilidade financeira são os principais objetivos políticos das modernas sociedades democráticas". Esses pressupostos da ciência econômica apresentados por Bresser-Pereira (2012) estão relacionados à ideia de que a Ciência Econômica é um "modelo aberto", em que o método de análise é o histórico-estruturalista e indutivo, instituições importam, os comportamentos psicológico-expectacionais dos indivíduos, como classes sociais, são relevantes e prevalecem incertezas na tomada de decisões, entre outros (Lawson, 1997; Chick, 2004).

${ }^{4}$ Para os autores, os métodos indutivo e histórico-indutivo terão o mesmo sentido, uma vez que dados fatuais e inferências a partir da histórica são importantes para a análise de Keynes.
} 
Nesse sentido, buscar-se-ão evidências de que o método indutivo está presente ao longo da obra de Keynes e a apresentação das evidências será feita, principalmente, por meio de citações e referências explícitas à obra do autor, como é comum às investigações sobre história das ideias. Para tanto, não somente o TP será usado como referência, mas o Tract on Monetary Reform (Tract), de 1923, o Treatise on Money (TM), de 1930, e a The General Theory of Employment, Interest and Money (GT), de 1936. Desta forma, a análise passará por praticamente três décadas de produção intelectual de Keynes, haja vista que o TP, embora publicado em 1921, foi escrito entre 1906 e 1908.

Além desta introdução, o artigo conta com outras quatro seções. Na segunda, será feita uma revisão da literatura pertinente às contribuições sobre a questão do método em Keynes. Na terceira serão resgatadas as concepções epistemológicas e filosóficas de Keynes expressas em seu TP. Na quarta seção, serão evidenciadas as passagens e os argumentos que corroboram a hipótese de que o método indutivo é uma evidência na obra de Keynes, por mais que se tenha ciência de que, devido ao seu pragmatismo, para ele o normativo e o convencional não faziam parte do real world, pois o tempo e as mudanças, enfim a historicidade, e a incerteza acabavam condicionando as tomadas de decisões. Por fim, apresentam-se as considerações finais.

\section{AS DIVERSAS INTERPRETAÇÕES SOBRE O MÉTODO DE KEYNES}

Como mostram Hegenberg (1976), Caldwell (1989) e Blaug (1999), vários são os métodos utilizados na busca pelo conhecimento. No que toca ao método indutivo há duas concepções possíveis. A primeira delas, segundo Keynes (1921), relaciona-se à Francis Bacon e John Stuart Mill e diz respeito a se conceituar a indução como a enumeração de evidências particulares observáveis a partir das quais se pode generalizar. A segunda concepção é a contribuição desenvolvida pelo próprio Keynes na TP, ao definir a indução não apenas como a generalização decorrente de um somatório de instâncias particulares, mas envolvendo também o uso da analogia. À enumeração das evidências, Keynes chama indução pura, ao passo que da soma dela com a analogia tem-se o método indutivo. Conforme Keynes (1921:, p. 316), "eu considerei melhor [...] usar indução em si para todos os tipos de raciocínios que combinem, de uma forma ou de outra, indução pura com analogia". 5

$\mathrm{Na}$ ciência econômica, como mostram Blaug $(1975,1999)$ e Corazza (2003), a diversidade de posições epistemológicas e metodológicas não é diferente do que

\footnotetext{
${ }^{5}$ É importante destacar que Blaug (1999) também argumenta que há um duplo sentido no termo indução, porém, relacionado não ao método de se generalizar a partir de casos particulares, mas à possibilidade de se demonstrarem as generalizações alcançadas. Por um lado, em seu uso lógico, a indução é o argumento que pode ser demonstrado e, assim, possui o caráter de certeza. Por outro lado, o sentido ordinário do termo se refere ao uso cotidiano que, contudo, não se preocupa com argumentos dotados de certeza.
} 
se vê na filosofia da ciência como um todo. A título de ilustração, Fonseca (2003) aponta o método como um dos pontos fundamentais da crítica de Malthus, empirista, a Ricardo, racionalista, enquanto que Germer (2003) mostra como o método de Marx foi central para que ele fizesse a crítica à economia política clássica. Não obstante, a crítica de Keynes ao método empregado por Ricardo e seus seguidores é uma constante na GT:

Ricardo oferece-nos a suprema realização intelectual, inalcançável aos espíritos fracos, adotando um mundo hipotético distante da experiência como se fosse o mundo da experiência e, então, nele vivendo consistentemente. Para a maioria de seus sucessores o senso comum não pode ajudar a rompê-lo [o mundo ricardiano] - sem prejuízo à sua consistência lógica. (1964, p. 192)

Por sua vez, são inúmeras as interpretações sobre o método em Keynes: o histórico-indutivo e a importância do empirismo; o Keynesian Kaleidics de Shackle (1969); as influências legadas por Marshall; o pluralismo metodológico; o método keynesiano próprio; e a utilização da lógica ordinária nas exposições metodológicas e teóricas do autor ao invés da lógica formal. Essas interpretações circunscrevem-se a debater o método científico tanto em Keynes quanto nos pós-keynesianos e conseguem ilustrar a diversidade de opiniões que circunda o referido assunto.

Dow (2001) destaca que embora Joan Robinson tenha sido a primeira a utilizar-se do termo teoria pós-keynesiana, suas contribuições não se preocuparam em debater o método de Keynes em particular, mas, sim, as diferença da agenda de pesquisa pós-keynesiana em relação à da síntese neoclássica. Embora Robinson não tenha realizado uma pesquisa sistemática sobre o método em Keynes, é possível perceber a preocupação dela em indicar que a teoria econômica preocupe-se em compreender, explicar e influenciar a história do real world (Robinson, 1984). Para tanto, a teoria "não pode ser uma doutrina ideológica (como a presunção em favor do laissez-faire) nem uma tautologia (como a fórmula quantitativa MV = PT)" (Robinson, 1984, p. 17).

Linha semelhante segue Eichner (1984, p. 192), para quem a teorização deve "explicar o conjunto de fenômenos empiricamente observáveis (que, no contexto social, são os acontecimentos históricos do mundo real)". Preocupando-se para além da consistência interna com a coerência empírica das teorias, o autor aponta que nas ciências sociais, em que experimentos controlados são improváveis, a validade de um determinado modelo econômico depende de ele gerar os resultados previstos quando praticados em alguma política pública. Davidson (1972) igualmente destaca o ponto de partida e de chegada das teorias keynesianas como sendo o real world, acrescentando o seu caráter não-ergódico e, portanto, incerto e em constante evolução histórico-institucional (Davidson, 1982-1983).

Estas contribuições podem ser sintetizadas como método histórico-indutivo, cuja ideia consiste em capturar, ao longo do tempo histórico, as evidências obser- 
váveis a partir das quais se poderá generalizar alguma teoria. O processo de investigação se inicia com a observação de certas regularidades da concretude do real world, em anteposição às proposições apriorísticas da tradição ortodoxa, e se conclui quando, por meio da indução, o fenômeno foi apreendido, compreendido e explicado. Para Bresser-Pereira (2009), na medida em que uma determinada generalização indutiva será utilizada para explicar a realidade histórica, o caminho de volta da teoria induzida para a realidade será a dedução. Desta forma, em franca oposição ao método hipotético-dedutivo utilizado pelos neoclássicos, o autor denomina o método de Keynes, bem como dos economistas clássicos como Smith, Marx e Malthus, como histórico-dedutivo, e afirma que "todos os modelos que partem de uma observação ou de um evento real seriam também histórico-dedutivos" (Bresser-Pereira, 2009, p. 167).

Abre-se, aqui, espaço ao argumento trazido por Carvalho (2003: 177) de que o método da GT apresentava Keynes enquanto "o agente econômico e [ao mesmo tempo] o investigador da economia". Ou seja, o método de Keynes o dispunha concomitantemente como teórico e teorizado, experimentador e observador do real world. Logo, Keynes parecia preocupar-se não somente com o mundo em si, mas com o mundo tal qual ele é percebido e esta percepção só poderá ser apreendida pelo teórico se seu método lhe permitir fazer parte do mundo a ser modelado. Em suma, Carvalho (2003) está ressaltando o empirismo, isto é, a experiência, como essencial à elaboração teórica de Keynes. Fonseca (2010) também salienta a importância conferida por Keynes à fundamentação empírica como substância para a obtenção do conhecimento, mas usa como modelo teórico para tanto o método pragmático americano, de Charles Peirce, William James e John Dewey.

Shackle (1969) foi outro importante autor a se debruçar sobre o método em Keynes e, diga-se de passagem, um dos primeiros a fazê-lo. Para ele, Keynes examina momentos de equilíbrio nas variáveis, porém, em um ambiente em que o comportamento humano baseado em expectativas influencia intempestivamente a trajetória econômica a ponto de os equilíbrios serem precários, não autorregulados, fora do pleno emprego e, sobretudo, cruciais, pois a dinâmica do sistema econômico dificilmente retorna a pontos de repouso exatamente iguais. Ao se unirem (i) a análise de momentos de equilíbrio, (ii) a condição de o ponto de equilíbrio analisado ser instável e (iii) o comportamento humano imprevisível, tem-se os três lados do método caleidoscópico, Keynesian Kaleidics, que sintetiza para Shackle (1969) o método de Keynes na GT.

Outra linha de investigação ressalta a herança legada por Marshall ao método de Keynes. Eichner (1984) aponta que Marshall era adepto da teoria evolucionária de Darwin e, assim, atentou-se para a apreensão da dinâmica dos fenômenos, preocupando-se com as leis de movimento dos sistemas, bem como de seus subsistemas componentes. Carvalho (1992) evidencia esta preocupação tanto em Marshall quanto em Keynes ressaltando a importância que ambos deram às mudanças da estrutura econômica ao longo do tempo, algo ilustrado por Crotty (1990) ao explicar como Keynes observa o real world para escrever a GT. No caso específico da dinâmica dos sistemas, Carvalho (1992) destaca que Keynes baseia-se na pers- 
pectiva expectacional para estabelecer a interação entre o curto e o longo prazos das economias monetárias da produção. ${ }^{6}$ Não obstante, são influências legadas a Keynes por Marshall, como apontam Carvalho (1992) e Chick e Dow (2001), o uso de instrumentos analíticos como as funções de oferta e de demanda e a noção de equilíbrio parcial, em que as influências entre duplas de variáveis são analisadas além de serem mensuradas por elasticidades. Em especial, Chick e Dow (2001) denominam este procedimento de pesquisa parcial de análise por segmentação/ compartimentação, e o entendem como o caminho encontrado por Marshall e Keynes para analisarem por etapas um fenômeno orgânico e complexo, tal qual a Economia.

Outra influência de Marshall sobre Keynes é a relevância de o desenvolvimento teórico se referenciar no comportamento humano médio (Carvalho, 1992). Não é por menos que as menções ao homem médio ou comum são uma constante nas obras de Keynes, como mostra a seguinte citação: "a prosperidade econômica é excessivamente dependente de uma atmosfera política e social que é agradável ao homem de negócios médio" (Keynes, 1964, p. 162, itálico adicionado). Indo nessa direção, Chick e Dow (2001) mostram a descrença de Marshall com relação às teorizações por demais abstratas e que poderiam acabar por retirar utilidade da ciência econômica, algo que Keynes (1964: 297), por sua vez, entendia poder ser "a grande falha dos métodos simbólicos pseudo-matemáticos de formalizar sistemas para a análise econômica”.

Corazza (2009) ressalta mais uma influência de Marshall sobre Keynes, que diz respeito à sugestão de Marshall de o método a ser usado depender das circunstâncias e da natureza do fenômeno. Não haveria um método a priori e todos os possíveis deveriam ser utilizados, desde que cabíveis à situação. Desta forma, segundo Corazza (2009, pp. 7-8), Keynes poderia ser considerado um pluralista metodológico, pois

Keynes faz uma combinação dos métodos indutivo e abstrato dedutivo adequados e aplicáveis à solução de problemas específicos. [...] Keynes não parece ter adotado nenhum desses caminhos extremos, nem unicamente o indutivo e muito menos o método a priori abstrato dedutivo [...] Ele pode ser definido como um pluralista na definição do método em economia.

Argumentação similar, porém sem destacar influência de Marshall, foi feita por O’Donnell (1989, p. 327): "metodologicamente, ele [Keynes] aceitou na economia a dedução, bem como a indução, e procurou envolver os modos de raciocínio tanto

\footnotetext{
${ }^{6}$ Kregel (1976) utiliza-se desta interação entre expectativas de curto e longo prazos para compor as três possíveis pontos de equilíbrio do sistema keynesiano, quais sejam: (i) equilíbrio estático, em que as expectativas de curto e longo prazo não se movem; (ii) equilíbrio estacionário, em que as expectativas de curto prazo se movem, mas não contaminam as de longo prazo; e (iii) equilíbrio móvel, em que as expectativas de curto prazo se movem e contaminam as de longo prazo.
} 
formais quanto não formais". Contudo, o argumento de fundo de O’Donnell (1989), diferentemente do caráter pluralista apontando por Corazza (2009), é o de que avesso a extremos em suas posições teóricas, Keynes teria percorrido o caminho do meio "em virtualmente todas as esferas, seja na filosofia, seja na economia ou na política” (O’Donnell, 1989, p. 325). Logo, o pluralismo de Keynes adviria de ele hesitar assumir posições radicais, implicando, inclusive, um leque de métodos assumidos pelo autor. Chick e Dow (2001) também arguem em mesmo sentido, mas com uma hipótese subjacente diferente à de Corrazza (2009) e O'Donnell (1989): para as autoras, Keynes utilizou-se de uma variedade de métodos por conta da complexidade dos sistemas abertos e orgânicos, tal qual o real world econômico.

Para Carabelli (1985), em linha com Carvalho (2003), o método de Keynes no TP faz com que a epistemologia do cientista econômico seja a mesma do agente econômico. Contudo, a autora, seguida por Souza (2003), encontra em Keynes uma postura que é, ao mesmo tempo, antiempiricista, antirracionalista e antipositivista, e, portanto, confronta a tese de ser Keynes um pluralista metodológico, como quer Corazza (2009), ou utilizar-se do indutivismo e do dedutivismo, como aponta O’Donnell (1989). A tese de Carabelli (1985) denota que Keynes é detentor de um método próprio, cujo fundamento encontra-se no TP, e que se sustenta em a probabilidade ser definida como uma relação cognitiva, de natureza orgânica entre indivíduo e todo, que usa da linguagem ordinária e não da lógica formal e que é mutável ao longo do tempo. Mesmo sustentando que Keynes se utiliza de método próprio, a autora não o sintetiza em um conceito ou nomenclatura e, assim sendo, resta apenas a noção de que "esta mistura de antiempiricismo e antirracionalismo era o núcleo da posição epistemológica peculiar de Keynes e torna difícil descrever a posição dele em termos simples" (Carabelli, 1985, pp. 151).

A tese de Carabelli (1985) alinha-se a duas discussões: uma sobre Keynes deter um método próprio e outra sobre o uso da lógica ordinária. Sobre a primeira discussão, há contraposições sobre estarem no TP as bases de um método próprio de Keynes. Carvalho (1988) aponta o TP como um esforço de Keynes em debater os fundamentos da tomada de decisão por intermédio da indução. Por sua vez, na GT, conforme Carvalho (1988), Keynes dedica-se a examinar como os indivíduos tomam decisões em contextos de informação inescapavelmente incompleta. Gerrard (1992) corrobora esse ponto de vista, pois sustenta que o Keynes do TP preocupa-se com temas mais especulativos enquanto que o Keynes da GT centra-se em questões de ordem prática. ${ }^{7}$

No entanto, Chick (1998) e Chick e Dow (2001) argumentam, assim como Carabelli (1985), que o método de Keynes ancora-se na lógica ordinária - ou humana, como chamam Chick e Dow (2001). De acordo com Costa (2002), a linguagem formal busca explicar os fenômenos por meio lógico-simbólico alheio a am-

\footnotetext{
${ }^{7}$ Este ponto guarda estreita relação com as discussões sobre a continuidade ou ruptura das posições filosóficas de Keynes ao longo de sua obra. Para mais, veja: O’Donnell $(1989,2002)$ e Bateman $(1989$, 1991).
} 
biguidades, enquanto a forma ordinária toma como modelo a linguagem do cotidiano, do espaço em que se vive. Esta forma de se entenderem e de se apresentarem os fenômenos tem íntima relação com o teórico e teorizado serem o mesmo sujeito, pois implica que o investigador faz perguntas e busca respostas usando a mesma lógica que os agentes comumente se utilizam. Na TP, Keynes faz clara alusão à lógica ordinária como meio de expressão teórica, ao argumentar que "estes escritores que se constrangem sob exagerada precisão [...] são algumas vezes meramente pedantes. Há muito a ser dito, em favor de se entender a substância do que se diz o tempo todo e nunca se reduzir o substantivo de seu argumento ao status mental de $x$ ou $y$ " (Keynes, 1921, p. 19).

Como se pode perceber, há uma dispersão de contribuições sobre o método em Keynes. ${ }^{8}$ No entanto, a diversidade de interpretações faz continuar a existir a seguinte pergunta: qual é o método de Keynes? Para os propósitos de um artigo, responder a esta questão de forma cabal é complexa, apesar de se especular sobre ele. Todavia, tendo como referência o resgate das contribuições originais de Keynes acerca da indução, entende-se que o método indutivo exerce influência em sua obra.

\section{OS INSIGHTS DE INDUÇÃO EM KEYNES}

Não é exagero se afirmar que o TP é uma obra sobre epistemologia. Neste particular, Keynes deixa claro nas primeiras páginas do livro o que diferencia o seu trabalho em relação ao estado das artes das discussões sobre a matéria:

$\mathrm{Na}$ maioria dos ramos da lógica acadêmica, como a teoria do silogismo ou a geometria do espaço ideal, todos os argumentos procuram ter certeza demonstrativa. Eles pretendem ser conclusivos. Mas muitos outros argumentos são racionais e pretendem ter certo peso sem serem conclusivos. Na metafísica, na ciência e na conduta [Ética] a maioria dos argumentos, sobre os quais nós habitualmente baseamos nossa crença racional, são admitidamente inconclusivos em maior ou menor grau. [...] O rumo dado pela História do Pensamento à trajetória da lógica estimulou o ponto de vista de que raciocínios duvidosos não se incluem no seu âmbito. Mas, no exercício concreto da razão não nos servimos apenas da certeza, nem consideramos irracional depender de um raciocínio duvidoso. (Keynes, 1921, p. 2)

Assim, no TP, Keynes lança as bases de uma teoria do conhecimento em que a probabilidade detém um papel central. No entanto, sua concepção de probabilidade não contabiliza frequência de eventos para a realização de cálculos que resul-

\footnotetext{
${ }^{8}$ Talvez isso tenha se refletido na própria metodologia da escola pós-keynesiana, pois, como apontam Caldwell (1989) e Dow (2001), vigora nesta teoria a ideia de pluralismo metodológico, embora ainda não se tenha sequer esta posição sido estabelecida no interior do paradigma pós-keynesiano.
} 
tem em inferências mais ou menos prováveis, mas relaciona premissas com argumentos que delas decorrem, sobre os quais se tem maior ou menor grau de convicção. Conforme Keynes “junto com o termo ‘evento’, que até aqui deteve tão importante lugar na fraseologia da matéria, eu dispensarei tudo [...] e será mais do que um progresso verbal discutir a verdade e a probabilidade de proposições, em vez da ocorrência e da probabilidade de eventos" (Keynes, 1921, p. 4).

O conhecimento é obtido por um processo que tem como ponto de partida o entendimento direto, que é o primeiro passo para que se possa conhecer. Havendo o entendimento, o indivíduo, por meio da intuição, alcança um determinado conhecimento direto. $\mathrm{O}$ entendimento direto decorre de experiências dos indivíduos que, por sua vez, envolvem (i) o uso dos sentidos, (ii) a compreensão de significados e (iii) a percepção de dados derivados dos fatos. Portanto, o entendimento direto constitui a experiência pelo uso dos sentidos, da compreensão e da percepção ${ }^{9}$ e a intuição que dele emana é peça-chave para a obtenção do conhecimento direto.

As proposições, por sua vez, são "os objetos do conhecimento e da crença" (Keynes, 1921, p. 11) e há dois conjuntos de proposições, as premissas e os argumentos (ou conclusões). As premissas são o conhecimento direto obtido pelo exame dos objetos e a conclusão é o resultado do raciocínio feito a partir das premissas. Em outros termos, em suas experiências os indivíduos alcançam conhecimento direto e deste são capazes de raciocinar outros, a que Keynes (1921) chama indiretos. Nas palavras do autor "deste modo, então, distingo entre conhecimento direto e indireto, entre aquela parte de nosso conhecimento que é baseada no conhecimento direto e naquela parte que é baseada no raciocínio" (Keynes, 1921, p. 13).

Se, em metáfora, o raciocínio é a ponte entre as premissas e a conclusão, a lógica é a estrutura inerente desta ponte e a probabilidade é a relação lógica que se trava, via raciocínio, entre os dois lados ligados pela ponte. Sobre esta probabilidade relacional há algum grau de convicção racional que o indivíduo possui nas conclusões que ele raciocina a partir de um conjunto de proposições conhecidas. Por isso, "sobre a probabilidade nada podemos dizer, além de que se trata de um grau de crença racional inferior ao da certeza; e, devemos dizer, se quisermos, que ela lida com graus de certeza" (Keynes, 1921, p. 14). A probabilidade refere-se, neste cenário, ao indivíduo deter maior ou menor grau de crença racional em seu argumento. Por analogia, a certeza é o maior grau possível em que se pode acreditar no raciocínio, isto é, ela é o grau máximo de crença racional.

A relação de probabilidade é devida à experiência individual e é, assim, subjetiva $^{10}$ e relativa ${ }^{11}$. Inclusive quando se tratam de axiomas lógicos, supostamente

\footnotetext{
${ }^{9}$ Keynes (1921) diz ainda que a memória também pode ser fonte de conhecimento; contudo, para a memória tornar-se o que é, ela foi anteriormente experiência, compreensão ou percepção.

${ }^{10}$ Neste ponto, cabe um esclarecimento: no TP, Keynes deixa claro que a lógica não é sujeita ao capricho humano e, portanto, é uma coisa em si, objetiva e independe do sujeito. Contudo, ao criticar o TP, Frank Ramsey argumenta que a lógica proposta por Keynes é subjetiva. Keynes, no obituário de Ramsey, aceita a crítica de Ramsey, argumentando que a lógica apresentada no TP é subjetiva ou humana. Para mais, veja Keynes (1972), Winslow (1986) e Chick e Dow (2001).

${ }^{11}$ Esta discussão tem intensa interface com a linha de pesquisa atomismo versus organicismo como
} 
mais objetivos, há subjetividade, pois "devemos admitir que isso [axioma lógico] também é relativo à constituição da mente humana e que esta constituição pode variar em algum grau de homem para homem" (Keynes, 1921, p. 17). O conhecimento está sujeito, portanto, às peculiaridades que surgem de diferentes introspecções, valores, expectativas individuais e outras características subjetivas que condicionam, ainda que intuitivamente, o comportamento humano (Keynes, 1973). Com tais bases de entendimento direto, "algum processo mental, difícil de ser descrito” (Keynes, 1921, p. 12), conduzirá o indivíduo ao conhecimento.

Em suma, no TP o conhecimento intuitivo é fundamental para a formação de uma crença racional. Por sua vez, o grau de crença racional sustenta-se no peso do argumento, ou seja, no conjunto de evidências disponíveis aos indivíduos no momento de formulação do conhecimento indireto. Quanto maior o conjunto de evidências disponíveis, maior confiança terá o sujeito nos argumentos que ele propõe. A probabilidade, então, tem uma relação significativa com a confiança nos dados disponíveis e não necessariamente com a frequência de disponibilidade dos dados, de forma que as ações dos indivíduos não podem ser baseadas em uma distribuição de probabilidade associada a todos os possíveis eventos futuros. ${ }^{12}$

Em linhas gerais, este é o conteúdo epistemológico do TP que serviu de base para Keynes apresentar a forma pela qual se obtém o conhecimento, bem como sua concepção de probabilidade. Assim sendo, resta perguntar: sob tal epistemologia, qual o método que permite ao raciocínio chegar do entendimento direto ao conhecimento direto e deste ao indireto? Em outras palavras, qual é o caminho pelo qual se alcança das experiências o conhecimento? Enfim, qual o método do conhecimento? Para Keynes "processos indutivos têm formado, claramente, em todos os tempos uma vital, habitual, parte da maquinaria da mente" (Keynes, 1921, p. 250).

O método indutivo segrega-se, para Keynes (1921), em duas técnicas: a analogia e a indução pura. A analogia é o raciocínio em que se comparam semelhanças e dessemelhanças entre evidências dos objetos. Ela pode ser em nível das evidências de entendimento direto para com conhecimento direto tanto quanto entre objetos conhecidos e outros que se desejam conhecer. $\mathrm{Na}$ indução por analogia, é fundamental que se apresentem analogias negativas, isto é, diferenças nos objetos, pois quanto maior é a variedade entre eles, melhor a generalização. A analogia positiva, por sua vez, são as semelhanças que os objetos detêm. Ao se conhecerem as semelhanças e dessemelhanças dos objetos particulares é possível ir além deles, ou seja, pode-se generalizar.

A indução pura é a generalização pela multiplicação dos casos particulares, em que o argumento ancora-se no somatório de evidências conhecidas que se agregam ao conhecimento direto. Contudo, pouco adianta a multiplicação de instâncias em

unidade relevante de teorização e análise em Keynes. Para mais, veja: Bateman $(1989,1991)$ e Davis (1989-1990), Carabelli (1985), Winslow (1986, 1989a, 1989b) e Rotheim (1989-1990).

${ }^{12}$ Não é demais ressaltar que, se no TP há o binômio probabilidade-peso, na GT o binômio é expectativa-estado de confiança. 
condições uniformes de experimentação. Caso se façam cem experimentos exatamente iguais, é bastante improvável que surjam evidências diferentes a ponto de se terem generalizações alternativas. Melhor é relacionar os objetos sob condições diferentes, no tempo e no espaço, para que se evidenciem as dessemelhanças e se eliminem as instâncias não essenciais à generalização.

Em suma, o método indutivo reúne em parte, analogia e, em parte, indução pura. A analogia é fortalecida pela indução pura, desde que se tenha a multiplicação de evidências por experiências não uniformes que agreguem dessemelhanças redutoras das possibilidades de generalizações alternativas dos objetos em comparação. Quanto mais (i) analogias negativas e positivas forem percebidas e (ii) casos particulares se somarem à experiência do indivíduo, maior o peso que ele terá em seu argumento, conduzindo-o à uma maior crença racional em suas proposições. Então,

o objetivo de se ampliar o número de evidências surge do fato de que estamos quase sempre conscientes de alguma diferença entre os objetos e de que mesmo onde a diferença conhecida é insignificante nós podemos suspeitar de que podem existir mais, especialmente quando nosso conhecimento dos objetos é muito incompleto. Toda nova evidência pode diminuir as semelhanças não essenciais entre os objetos e por introduzir-se uma nova diferença amplia-se a Analogia Negativa. Por esta razão, e somente por esta razão, novas instâncias são necessárias. (Keynes, 1921, p. 269)

Por implicar conclusões a partir de evidências particulares, o método indutivo sempre traz consigo a incerteza, haja vista o célebre problema da indução de David Hume. Contudo, Keynes (1921) não enxerga qualquer problema nisso, pois sua probabilidade não intenta a verdade da relação entre premissas e conclusão, mas a razoabilidade dela. Decorre disto, no $T P$, a probabilidade lidar com graus de certeza em um conhecimento, isto é, em uma generalização. O conhecimento, mesmo incerto e não terminante, é lógico e válido, mesmo quando não é dotado de verdade demonstrativa, como o é um teorema. ${ }^{13}$

Quando o indivíduo induz, considera-se que o conhecimento direto do qual decorre sua conclusão é verdadeiro. Entretanto, a condição de verdade das premissas é um requisito para que delas se possa concluir e nada implica que a referida verdade seja inquestionável. Pelo contrário, coerente com sua concepção metodológica, Keynes argumenta que

não há nada de novo na suposição de que a probabilidade de uma teoria gira em torno das evidências em que ela se apoia; e é comum afirmar que uma opinião provável com base nas evidências inicialmente à mão, diante de outras informações tornou-se insustentável. Enquanto

\footnotetext{
13 Nas palavras de Keynes (1921, p. 284), “mas é certo que Newton e Huygens só foram razoáveis quando suas teorias eram verdadeiras e que seus erros foram frutos de fantasias desordenadas?".
} 
muda nosso conhecimento ou nossas hipóteses, nossas conclusões têm novas probabilidades, não em si, mas em relação às novas premissas. (Keynes, 1921, p. 7)

De acordo com Keynes (1921: 282), "a utilidade da indução depende, sem dúvidas, do conteúdo atual da experiência” e, assim, a experiência sensorial é um meio de entendimento, de conhecimento, de formulação de hipóteses e de se conferir utilidade prática ao saber via indução. No entanto, a forma pela qual Keynes concebe a indução, e principalmente pelo papel cumprido pela analogia, não a restringe à matéria do fato, mas permite seu uso em níveis abstratos (haja vista a própria experiência pela compreensão de significados), indo além da indução pura histórico-indutiva (ou histórico-dedutiva, à la Bresser-Pereira, 2012). Nestes moldes, a indução em Keynes incorpora os referidos métodos, mas não se restringe a eles, podendo-se considerá-los como formas de expressão do indutivismo em Keynes. A indução, desta forma, pode ser utilizada nas diversas disciplinas científicas, inclusive naquelas que se relacionam ao estudo do comportamento humano, como as ciências morais e que Keynes (1973) entendia ser a natureza da Economia. Logo,

eu não quero sugerir pelo uso do termo indutivo que estes métodos [analogia e pura indução] estão necessariamente confinados aos objetos da experiência fenomênica e àquilo que é por vezes chamado questões empíricas; ou evitar desde o princípio a possibilidade do uso deles em investigações abstratas e metafísicas. (Keynes, 1921, p. 252)

O método indutivo, sob a lógica da probabilidade de Keynes, é hábil a tratar o fenômeno econômico, não somente porque apresenta uma teoria do conhecimento relacionada ao modo pelo qual os sujeitos raciocinam, imbuídos de "motivos, expectativas, incertezas psicológicas" (Keynes, 1973, p. 300), mas, também, por permitir que, diante de seu caráter inconclusivo, a teoria evolua ao longo do tempo, pela inclusão de novos entendimentos e conhecimentos. Muito embora, a indução não consiga chegar a "generalizações completamente acuradas" (Keynes, 1964, p. 247), os modelos por ela construídos são abertos, pela complementaridade entre analogia e pura indução, à incorporação do conhecimento novo. Mesmo diante de um material inconstante e heterogêneo, consegue-se "segregar os fatores semipermanentes e relativamente constantes daqueles que são transitórios ou flutuantes a bem de desenvolver uma forma lógica de se pensar sobre os últimos e de entender a sequência de tempo em que eles surgem nos casos particulares" (Keynes, 1973, p. 297). Não custa lembrar que tais fatores flutuantes ou transitórios são os que Keynes (1964, p. 247) argumenta, na GT, que "na prática exercitam uma influência dominante sobre nosso objeto" e relacionam-se àquilo que Chick e Dow (2001) chamaram de análise por segmentação/compartimentação.

Ademais, o princípio da unidade orgânica torna a incerteza devida à indução ainda mais radical. Consoante Keynes (1973), por causa da unidade orgânica o todo é maior do que o somatório das partes que o compõem e, portanto, as unida- 
des individuais não podem ser redutíveis a partes iguais, conhecidas e previsíveis. Um indivíduo desconhece a forma pela qual o outro elenca evidências para generalizar sendo que a decisão de cada um tem o poder de alterar o todo para além daquilo esperado pelo agente. Não bastasse ser o ambiente desconhecido, ele é ainda passível de alteração dinâmica pelas decisões que os indivíduos tomam, de forma fragmentada e descoordenada. Assim, o conhecimento e o grau de crença racional dos indivíduos em suas conclusões podem oscilar de maneira intempestiva, pois as premissas nas quais se ancoram alteram-se com constância.

Não obstante, o conhecimento por indução corrobora, ainda, o caráter nãoergódico da realidade, destacado por Davidson (1982-83). Como aponta Hayes (2006), a nãoergodicidade é uma característica inerente dos sistemas/modelos abertos (Lawson, 1997) e resulta do fato de que as evidências não se distribuem com média zero no espaço amostral ou nos dados temporais, de forma que o valor esperado delas não pode ser calculado. Mesmo no caso especial de isso acontecer - ou seja, a ergodicidade dos modelos neoclássicos - a indução a partir de dados particulares não permite a certeza do conhecimento, pois, como afirma Keynes (1921), a regularidade de certos fenômenos, como o sol levantar-se todas as manhãs é, no máximo, uma correlação indutiva e não um conhecimento certo dos fenômenos objetivos. Uma nova evidência, mesmo que se posicione na média da amostra, pode ocasionar argumentos completamente novos que alteram por completo o antigo status quo. Logo, melhor "é a crença que o sol deve nascer amanhã, ao invés da crença de que ele sempre nascerá" (Keynes, 1921, p. 298).

Para que se possa concluir sobre como o método indutivo é importante em Keynes, buscam-se evidências de que o exposto no TP tenha sido praticado pelo autor ao longo de sua obra. Nesse sentido, a próxima seção vai nessa direção. Como mencionado na Introdução do artigo, o recorte analítico dar-se-á sobre três obras econômicas de Keynes, quais sejam: Tract, TM e GT. ${ }^{14}$

\section{AS EVIDÊNCIAS DO MÉTODO INDUTIVO EM KEYNES}

Podem-se perceber evidências de que Keynes se utiliza da epistemologia e da metodologia expressas em seu TP sob dois âmbitos: (i) no comportamento do agente teorizado e (ii) no seu método enquanto teórico. Diga-se de passagem, o primeiro âmbito é o mais comumente debatido na literatura; contudo, também no segundo é possível notar o papel do método indutivo em Keynes como uma das formas pela qual ele se apodera do fenômeno a ser compreendido. Não obstante, os dois âmbitos são a expressão daquilo que Carvalho (2003) pontua como o investigador enquanto agente econômico. O teórico é partícipe da realidade tanto quanto um agente e, então, consegue experimentá-la e teorizá-la.

Pois bem, se para fins de epistemologia e metodologia o tempo pode não ser

${ }^{14}$ Nas referências, veja-se: Keynes (1971a, 1971b, 1964), respectivamente, ao Tract, ao TM e à GT. 
uma variável fundamental, para a investigação econômica ele é. É ao longo dele que as decisões dos agentes se concretizam, inclusive aquelas sobre a ampliação de sua riqueza. Sendo o conhecimento incerto, não há como conhecer qual a forma desta concretização, se vantajosa ou não. Por conta disso, os agentes criam expectativas, e não certezas, sobre o futuro. Essa é a aplicação da noção keynesiana de probabilidade, conforme atestam, na GT, as palavras de Keynes (1964, p. 148):

por "muito incerto" eu não quero significar a mesma coisa que "muito improvável". Cf. meu Tratado sobre a Probabilidade [...] [e] o estado da expectativa a longo prazo, sobre a qual se baseiam nossas decisões, não depende somente do prognóstico mais provável que podemos formular. Depende, também, da confiança com que fazemos este prognóstico.

Ainda sobre a incerteza no âmbito do agente, no Tract os indivíduos, a partir de seus hábitos, reservam encaixes monetários e, assim, influenciam o nível de preços. No TM, as expectativas se traduzem tanto na taxa natural de juros, que iguala poupança e investimento, quanto nos comportamentos bull e bear dos agentes no mercado financeiro, bem como na relação entre taxa de desconto e ganhos esperados dos agentes. Pode-se ainda ressaltar na GT o confronto, dependente do conhecimento incerto que os agentes possuem sobre o futuro, entre a eficiência marginal do capital e a preferência pela liquidez e sua consequente taxa de juros. Assim, a dinâmica econômica torna-se condicionada ao modo pelo qual os agentes absorvem e raciocinam ao longo do tempo e sob incerteza.

Não obstante, é notável que analogia e indução pura são fundamentais para a tomada de decisão do agente. No TM a igualdade entre poupança e investimento depende da equivalência entre a taxa de juros do mercado e a taxa de juros natural. Logo, o comportamento do agente e a dinâmica econômica são influenciados pela analogia que o agente faz entre o juro natural e o juro de mercado. Este ele conhece no presente, mas seu comportamento futuro não. Da expectativa, por analogia, que ele fizer entre o presente e o futuro dependerá sua maior ou menor alocação de moeda na circulação financeira do capital. Na GT, como mostra Hesse (1987), a eficiência marginal do capital e a preferência pela liquidez ancoram-se no pensamento, por analogia, de que as condições conhecidas do presente se assemelharão às do futuro.

Como visto, para a indução pura somam-se evidências que são acessíveis ao indivíduo. Caso este seja um empresário buscando elementos para decidir sobre a ampliação de seu estoque de capital produtivo, lhe serão conhecidos o valor do salário mínimo, a taxa de desemprego, o nível de preços e o grau da concorrência, entre outros fatores. Além disso, a política econômica também é interpretada como uma evidência sobre o ambiente de negócios. Por isso ela deve atuar, por um lado, buscando estabilizar automaticamente o ciclo econômico e, por outro lado, estruturando um cenário institucional propício aos investimentos produtivos, como argumentam Ferrari Filho e Terra (2011). Por sua vez, as convenções destacadas por Keynes na GT também representam conhecimento sobre o qual se ancora o 
animal spirits dos empresários. De todas estas formas, multiplicam-se as evidências diretamente conhecidas de maneira que os argumentos dos investidores sobre o futuro tenham mais peso e, portanto, lhes implique maior estado de confiança.

Se os agentes lidam com o resultado incerto de suas ações, o mesmo vale para as autoridades econômicas. As políticas monetária e cambial, por exemplo, operam buscando influenciar o comportamento dos agentes e, portanto, não são de impacto direto sobre a atividade econômica. Não é por menos que no Tract e no TM, livros que investigam, notadamente, os fatores que fazem variar o nível de preços e, por consequência, o valor da moeda, Keynes é cético sobre os resultados passíveis de serem alcançados pela política monetária. $\mathrm{Na} G T$, em que a variável preço é secundária em relação às variáveis emprego e produto, o ceticismo de Keynes com relação à política monetária parece ser mais profundo do que nos livros anteriores, à medida que afirma: "de minha parte eu sou presentemente cético acerca do sucesso de uma política meramente monetária no sentido de influenciar diretamente a taxa de juros" (1964, p. 164). Por isso, a preferência de Keynes é pela política fiscal, cujo impacto na demanda agregada é imediato (Ferrari Filho e Terra, 2011). De todo modo, por funcionar como um conhecimento direto ao indivíduo, desde o Tract, afirmava Keynes,

o remédio residirá, de preferência, em se controlar o padrão de valor [...] colocando-se em marcha algum fator contrário à tendência. Mesmo se a política não for completamente bem sucedida, tanto em compensar as expectativas ou em evitar movimentos atuais, ela será uma melhoria na política de ficar-se quieto. (1971a, p. 35)

Note-se, portanto, que nas obras econômicas analisadas, a presença da indução tal qual desenvolvida por Keynes no TP é evidente. Cabe procurar, agora, elementos que permitam localizar o papel do método indutivo na abordagem que Keynes realiza para apreender o fenômeno econômico. Assim sendo, são notáveis as diversas alusões à experiência ao longo do Tract, do TM e da GT. Nesse particular, vários são as funções dela, mas todas se referem à coleta de evidências para se abordar o sistema econômico. A experiência serve como fonte de problemas para investigação, a exemplo do Tract, em que "as flutuações no valor da moeda desde 1914 foram em uma escala tão grande a ponto de constituir, com tudo o que ela envolve, um dos mais significantes eventos na história econômica moderna" (1971a, p. 1). ${ }^{15} \mathrm{~A}$ experiência, ademais, inspira categorizações para se modelarem comportamentos, tais como "a segunda categoria de depósitos de poupanças compreende o que, em linguagem emprestada das bolsas de valores, nós chamaremos de posição bear" (Keynes, 1971b, p. 223).

A experiência também é base para Keynes lançar e validar hipóteses, como no

\footnotetext{
${ }^{15}$ Note-se, o próprio objeto do livro, Um tratado sobre a reforma monetária, decorre da observação deste fenômeno por Keynes.
} 
caso das quatro condições de estabilidade que impedem movimentos cíclicos intensos no sistema econômico. Nas palavras do autor, “ora, como estes fatos da experiência não se seguem de necessidade lógica, pode-se supor que o ambiente e as propensões psicológicas do mundo moderno são de um tipo tal que produzem este resultado [estabilidade]" (Keynes, 1964, p. 250). E, reiteradamente ao longo do capítulo 18 da GT, “não obstante, a experiência mostra” (Keynes, 1964, p. 252) ou "nossa terceira condição concorda com nossa experiência da natureza humana" (Keynes, 1964, p. 252), até que, por fim, “deste modo nossas quatro condições em conjunto são adequadas para explicar as características bem conhecidas de nossa experiência corrente" (Keynes, 1964, p. 254).

Ainda no referido capítulo da GT há evidência da indução, dada inclusive pelo título dele: A Teoria Geral do Emprego Reafirmada. É nele que Keynes confirma a generalidade de sua teoria, após ter examinado as relações causais de diversas instâncias particulares, tais como: o que causa o emprego? O que causa a demanda efetiva? O que causa o consumo? O que causa o investimento? O que causa a taxa de juros da moeda? Por que a moeda e não qualquer outro ativo? Ao se investigar cada uma destas variáveis, o que se pode generalizar? Induz-se e reafirma-se, a partir das premissas do conhecimento direto, o argumento da GT.

Raciocínios por analogia também estão presentes, notadamente nas discussões mais abstratas. Em especial, a forma pela qual Keynes questiona na GT o segundo postulado da Economia Clássica. O referido postulado clássico aponta que reduções no salário nominal implicam menores salários reais (ou aumentos em sua identidade, a desutilidade marginal do trabalho) e conduzem ao aumento do desemprego. Por analogia, variações dos preços, dados os salários nominais, conduzem à redução dos salários reais (ou aumentos na desutilidade marginal do trabalho) e causam aumento do desemprego? Esta analogia é falsa, pois, não se veem trabalhadores deixando seus empregos por conta de aumentos no custo de vida. Keynes, então, parte para a indução pura, somando-a à analogia, o que lhe permite, por um lado, concluir um problema na teoria Clássica e, por outro lado, buscar soluções para o problema teórico. Neste contexto,

ora, a experiência ordinária nos diz, sem dúvidas, que a situação em que o trabalhador estipula (...) os salários monetários ao invés dos reais, longe de ser uma mera possibilidade, é o caso normal. Enquanto os trabalhadores resistirão sempre a uma redução dos seus salários monetários, não é da prática deles abandonar seus empregos sempre que houver um aumento nos preços dos bens-salário. (Keynes, 1964, p. 9)

Como se não bastasse, somem-se as seguintes observações factuais: "mas, seja lógico ou não, a experiência mostra que é este o comportamento dos trabalhadores" (Keynes, 1964, p. 9) e "ademais, o argumento de que o desemprego que caracteriza a depressão é devido à recusa do trabalho de aceitar uma redução em seus salários monetários não é claramente atestada pelos fatos” (Keynes, 1964, p. 9). Por fim, 
"estes fatos da experiência são, prima facie, base para se questionar a adequação da teoria clássica” (Keynes, 1964, p. 9).

Outra analogia relevante da GT se expressa na abordagem do fenômeno juros (Keynes, 1964, cap. 13). Como afirma a teoria Clássica, sendo os juros a recompensa pela espera, por consequência, toda espera deve ser recompensada. Por analogia, por que a espera em moeda, então, não paga juros? Ao não poder responder a tal questão, corrobora-se que a teoria Clássica não pode ser geral, pois ela não lida com todas as vicissitudes do sistema econômico. Por fim, saliente-se a analogia pela qual se pode compreender a relação entre investimento produtivo, taxa de juros e moeda, que resulta de Keynes (1964, cap. 17). Todos estes objetos possuem naturezas semelhantes por serem meios de se reservar valor; contudo, são diferentes em qualidades como risco, custo de carregamento e prêmio de liquidez. Logo, pelo exame das semelhanças e dessemelhanças, podese concluir que eles sejam alternativos uns aos outros. E, conhecendo as características e as influências de cada um destes objetos, pôde Keynes (1964) modelar os determinantes do emprego e do produto.

Diante de inúmeras evidências, parece haver pouca dúvida de que o método indutivo foi um importante caminho para Keynes construir sua obra. Por conseguinte, o autor não somente defendeu a validade dele enquanto meio de se conhecer, mas aplicou-o para elaborar suas teorias sobre fenômenos econômicos. Além disso, coerente com sua posição epistemológica, em que o conhecimento por indução é inconclusivo e, portanto, novas evidências podem levar a novas conclusões, seus objetos e suas concepções teóricas foram, em parte, se alterando ao longo do tempo. Exemplo notável é a teoria quantitativa da moeda, dada como válida por Keynes no Tract, pelo menos no longo prazo, e refutada na GT. Enfim, "uma teoria científica não pode pretender que os fatos se ajustem a suas próprias hipóteses" (Keynes, 1964, p. 276) e, assim sendo, a cada incorporação de conhecimentos, as teorias se adaptam, para perseguirem "os fatores que, principalmente, determinam o nosso quaesitum” (Keynes, 1964, p. 247).

\section{CONSIDERAÇÕES FINAIS}

Como visto, Keynes buscou validar a indução não somente como um método científico, mas, também, como um caminho intuitivo pelo qual os sujeitos, em geral, podem conhecer. Talvez, o papel do método indutivo seja uma das facetas mais importantes da revolução teórica keynesiana, pois investigador e investigado são "agentes" comuns, usam da mesma lógica ordinária, observam, sentem e experimentam o real world da mesma forma, algo fundamental para que a teoria detenha não um significado contemplativo, mas, sim, prático de intervenção na realidade, principalmente em um contexto econômico sujeito a instabilidades e desequilíbrios, como é o caso de economias monetárias. 
Embora a questão metodológica em Keynes esteja em aberto, os argumentos e as evidências apresentadas neste artigo permitem concluir que o método indutivo está bastante presente na obra de Keynes, tanto na forma pela qual o empresário, sujeito teorizado, age, quanto como método de abordagem que permitiu ao autor conceber o fenômeno econômico como uma economia monetária da produção. $\mathrm{O}$ método histórico-indutivo relaciona-se intimamente com a indução de Keynes e, assim sendo, é possível inferir que o indutivismo de Keynes fornece as bases para o referido método, podendo ser ele considerado como uma forma específica da indução, em especial, da indução pura.

Tão importante quanto isso é enfatizar que os fundamentos epistemológicos e metodológicos dele não estão circunscritos apenas às influências recebidas ou são apropriações que ele faz de métodos utilizados por outros teóricos. Keynes deu-se o trabalho de conceber um aparato intelectual próprio que lhe permitiu desenvolver seus trabalhos econômicos e que oferece explicações funcionais para a trajetória histórica do sistema. Seus pressupostos epistemológicos e metodológicos buscam, e apresentam fundamentos lógicos para tanto, tornar válido o conhecimento incerto, elemento fundamental para explicar o comportamento de uma economia monetária da produção. Logo, uma importante conclusão a que se pode chegar neste artigo é que a incerteza inerente à ação dos agentes não é um pressuposto da teoria econômica de Keynes, mas é uma decorrência de sua teoria do conhecimento, pois "nosso conhecimento, contudo [...] é frequentemente obtido indutivamente, e compartilha a incerteza a que todas as induções são passíveis" (Keynes, 1921, p. 108).

Por fim, ressaltem-se duas observações: por um lado, sendo a Economia, para Keynes, uma ciência moral, a indução permite estabelecer a racionalidade da decisão individual em um mundo incerto. Nesse sentido, Keynes não observava a indução apenas como um método científico, mas como a forma pela qual os sujeitos em geral conhecem. Por outro lado, embora o artigo tenha explorado o papel da indução em Keynes e o método indutivo, sua vasta e variada obra deve, certamente, utilizar-se de outros métodos.

\section{REFERÊNCIAS BIBLIOGRÁFICAS}

Bateman, B. W. (1989). "Human logic” and Keynes' economics: a comment”. Eastern Economic Journal, v. 15, nº1: 63-67.

Bateman, B. W. (1991). “Das Maynard Keynes problem”. Cambridge Journal of Economics, v. 15, nº1: 100-111.

Blaug, M. (1975). "Kuhn versus Lakatos, or paradigms versus research programmes in the history of economics". History of Political Economy, v. 7, nº 4: 269-280.

Blaug, M. (1999). Metodologia da Economia. São Paulo: EDUSP.

Bresser-Pereira, L. C. (2009). "Os dois métodos e o núcleo duro da teoria econômica”. Revista de Economia Política, v.29, n² (114): 163-190, abril-junho.

Bresser-Pereira, L. C. (2012). "Why Economics should be a modest and reasonable Science” Journal of Economic Issues, v.XLVI, n²: 291-301, June.

Caldwell, B. J. (1989) "Post-Keynesian methodology: an assessment”. Review of Political Economy, v. $1, \mathrm{n}^{\circ} 1$, pp. 43-64. 
Carabelli, A. (1985). "Keynes on cause, chance and possibility”. In: Lawson, T.; Pesaran, H. (eds.). Keynes' Economics Methodological Issues. Armonk: M. E. Sharpe, pp. 151-180.

Carvalho, F. J. C. (1988). "Keynes on probability, uncertainty and decision making”. Journal of Post-Keynesian Economics, v. 11, $\mathrm{n}^{\circ} 1:$ 66-81.

Carvalho, F. J. C. (1992). Mr.Keynes and the Post Keynesians. Aldershot: Edward Elgar.

Carvalho, F. J. C. (2003). "Características essenciais do método de Keynes na Teoria Geral”. In: Corazza, G. (org.). Métodos da Ciência Econômica. Porto Alegre: UFRGS, pp. 175-188.

Chick, V. (1998). “On knowing one's place: the role of formalism in Economics”. The Economic Journal, v. 108, n 451: 1859-1869.

Chick, V. (2004). “On open systems”. Revista Brasileira de Economia Política, v.24, nº 1 (93): 3-16, janeiro-março.

Chick, V.; S. Dow (2001). “Formalism, logic and reality: a Keynesian analysis.” Cambridge Journal of Economics, v. 25, n' 6: 705-721.

Corazza, G. (org.) (2003). Métodos na Ciência Econômica. Porto Alegre: UFRGS.

Corazza, G. (2009). “Aspectos metodológicos do pensamento de Keynes”. Anais do XXXVII Encontro Nacional de Economia. Foz do Iguaçu: ANPEC.

Costa, C. (2002). Filosofia da linguagem. Coleção Passo a Passo Filosofia, v.5. Rio de Janeiro: Jorge Zahar.

Crotty, J. R. (1990). "Keynes on the stages of development of the capitalist economy: the institutional foundations of Keynes's methodology" Journal of Economic Issues, v. 24, $\mathrm{n}^{\circ}$ 3: 761-780.

Davidson, P. (1972). Money and The Real World. Londres: Macmillan.

Davidson, P.. (1982-83). "Rational expectations: a fallacious foundation for studying crucial decision making process". Journal of Post Keynesian Economics, v. 5, n 2: 182-198.

Davis, J.B. (1989-1990). "Keynes and organicism”. Journal of Post Keynesian Economics, v. 12, $\mathrm{n}^{\circ}$ 2: 308-315.

Dow, S. (2001). "Post Keynesian methodology”. In: Pressman, S.; Holt, R. P. F.(eds.). A New Guide to Post-Keynesian Economics. Londres: Routledge, pp. 12-20.

Eichner, A. S. (1984). "Mirando hacia adelante". In: Eichner, A. S. (ed.). Economía PostKeynesiana. Madrid: Hermann Blume, pp. 185-204.

Ferrari Filho, F.; F.H.B.Terra (2011). "As disfunções do capitalismo na visão de Keynes e suas proposições reformistas”. Revista de Economia Contemporânea, v.15, n 2: 271-295.

Fonseca, P. C. D. (2003). “O método como tema: controvérsias filosóficas, discussões econômicas”. In: Corazza, G. (org.). Métodos da Ciência Econômica. Porto Alegre: UFRGS, pp. 17-34.

Fonseca, P. C. D. (2010). "Keynes: o liberalismo econômico como mito". Economia e Sociedade, v. 19, $\mathrm{n}^{\circ}$ 3: 425-447.

Gerrard, B. (1992). "From a treatise on probability to the General Theory: continuity or change in Keynes's thought?" In: Gerrard, B.; Hillard, J. (eds.). The Philosophy and Economics of J. M. Keynes. Aldershot: Edward Elgar, pp.80-95.

Germer, C. (2003). "A relação abstrato/concreto no método da economia política”. In: Corazza, G. (org.). Métodos da Ciência Econômica. Porto Alegre: UFRGS, pp. 61-92.

Hayes, M. (2006) "Financial bubbles". In: Arestis, P.; Sawyer, M. (eds.) A Handbook of Alternative Monetary Economics. Cheltenham: Edward Elgar, pp. 420-437.

Hegenberg, L. (1976). Leis, teorias e método. Etapas da Investigação Científica, v. 2. São Paulo: EDUSP. Hesse, M. (1987). “Keynes and the method of analogy”. Topoi, v. 6, n¹: 65-74.

Keynes, J. M. (1921). Treatise on Probability. London: MacMillan and Co. Disponível em: http://www. gutenberg.org/ebooks/32625. Acesso em dezembro de 2012.

Keynes, J. M.. (1964). The General Theory of Employment, Interest and Money. Nova York: HBJ Book.

Keynes, J. M. (1971a). A Tract on Monetary Reform (CWJMK, v.IV). London: Cambridge University Press.

Keynes, J. M.. (1971b). A Treatise on Money: the pure theory of money (CWJMK, v.V). London: Cambridge University Press. 
Keynes, J. M. (1972). Essays in Biography (CWJMK, v. X). London: Cambridge University Press.

Keynes, J. M. (1973). The General Theory and After: defense and development (CWJMK, v. XIV). London: Cambridge University Press.

Kregel, J. (1976). "Economic methodology in the face of uncertainty: the modeling methods of Keynes and the post-Keynesians". The Economic Journal, 86, n 342: 209-225.

Lawson, T. (1997) Economics and Reality. London: Routledge.

O’Donnell, R.M. (1989). Keynes: Philosophy, Economics and Politics. New York: St.Martin's Press.

O'Donnell, R.M. (2002). "The thick and the thin of controversy: a critique of Bateman on Keynes". Macquarie Economics Research Papers, v. 4. Disponível em: http://www.econ.mq.edu.au/Econ_ docs/research_papers2/2002_research_papers/4-2002_ODonnell.PDF, acesso em março de 2013.

Robinson, J. (1984). Prólogo. In: Eichner, A. S. (ed.). Economía PostKeynesiana. Madrid: Hermann Blume, pp. 11-25.

Rotheim, R. J. (1989-1990). "Organicism and the role of individual in Keynes's thought”. Journal of Post-Keynesian Economics, v. 12, nº 2: 316-326.

Shackle, G. (1969). Um Esquema da Teoria Econômica. Rio de Janeiro: Jorge Zahar.

Souza, M. G. (2003). "Método e visão de mundo em Keynes: uma abordagem alternativa”. In: Corazza, G. (org.). Métodos da Ciência Econômica. Porto Alegre: UFRGS, pp. 153-174.

Winslow, E. G. (1986). “Human Logic” and Keynes' Economics”. Eastern Economic Journal, v. 12, nº4: 413-430.

Winslow, E. G. (1989a). “Human logic” and Keynes’ Economics: a reply to Bateman”. Eastern Economic Journal, v. 12, $\mathrm{n}^{\circ} 4: 67-70$.

Winslow, E. G. (1989b). “Organic interdependence, uncertainty and economic analysis”. Economic Journal, v. 99, nº 398: 1173-1182. 